\title{
DESAFIOS DA ATENÇÃO BÁSICA NO CUIDADO À POPULAÇÃO EM TEMPO DE PANDEMIA
}

\author{
Rosa Maria Godoy Serpa da Fonseca' \\ ORCID: 0000-0001-9440-0870 \\ Lucimara Fabiana Fornari' \\ ORCID: 0000-0002-8655-6549 \\ Rafaela Gessner Lourenço" \\ ORCID: 0000-0002-3855-0003
}

'Escola de Enfermagem da Universidade de São Paulo. São Paulo, São Paulo, Brasil.

" Universidade Federal do Paraná. Curitiba, Paraná, Brasil.

Autor Correspondente: Rosa Maria Godoy Serpa da Fonseca E-mail:rmgsfon@usp.br

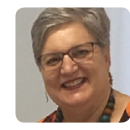

Como citar:

Fonseca RMGS, Fornari LF, Lourenço RG. Desafios da atenção básica no cuidado à população em tempo de pandemia. In: Teodósio SSS,

Leandro SS (Orgs.). Enfermagem na atenção básica no contexto da COVID-19. 2.ed.rev. Brasília, DF : Editora ABEn, 2020. p. 4-10. (Série Enfermagem e Pandemias, 3). https://doi.org/10.51234/aben.20.e03.c01
A pandemia que vivemos é um exemplo pleno do que um grego trágico chamaria de ação da fortuna: ainda que tenhamos algum controle sobre ela (técnico, político, médico), a pandemia écega, violenta, cruel, sem nenhuma intenção inteligente de sê-lo, portanto, um caso clássico da fortuna cega dos trágicos. Fortuna aqui é acaso, contingência, nada a ver com o uso comum de fortuna como grana ${ }^{(1)}$.

\section{INTRODUÇÃO}

Mais que um agravo biológico provocado por um vírus, a pandemia da COVID-19 deve ser compreendida como um fenômeno histórico-social, reflexo da organização político-econômica e sanitária vigente no século XXI e fruto do avanço do capitalismo às custas do acirramento das condições de exploração do sistema ecológico e social, com evidente piora das condições de vida da maior parte da população do planeta. Nesse contexto, instalado o agravo, evidenciou também as fragilidades e potencialidades dos sistemas de atenção à saúde para o enfrentamento desse problema de caráter mundial.

No momento de produção deste texto (julho de 2020), o Brasil registra perto de 80 mil óbitos e mais de dois miIhões de pessoas infectadas. É o segundo país do mundo em termos de incidência da doença, apenas ultrapassado pelos Estados Unidos da América ${ }^{(2)}$.

E a tendência é piorar, dado que a curva de incidência da doença ainda é ascendente. Porém, há que se ter em conta que a situação ainda poderia ser pior. Só não o é porque temos um Sistema Único de Saúde (SUS), de abrangência universal, equânime e solidário - apesar das suas fragilidades - que tem garantido, ainda que com inúmeras dificuldades, conter um pouco o agravamento da situação.

No Brasil, o advento da pandemia da COVID-19 agravou enormemente uma crise sanitária já vigente, coincidindo e agravando duas outras crises que também já se encontravam em curso, a política e a econômica. A opção das últimas gestões do Governo Federal pelo crescimento 
econômico com base na contenção de gastos públicos, as chamadas políticas de austeridade - com inegável favorecimento das classes sociais privilegiadas, formadas pelos detentores dos meios de produção do setor privado - já vinha ferindo de morte as populações socialmente mais vulneráveis e que constituem os principais usuários dos serviços públicos de saúde, educação, assistência social, segurança, entre outros.

O que a pandemia tem provocado é uma crise social sem precedentes, fruto da alquimia das crises econômica, política e sanitária, acarretando graves consequências para a qualidade de vida e saúde dos grupos historicamente desfavorecidos como os pobres, pretos, mulheres, idosos, indígenas, crianças, ou seja, a maioria subjugada do mundo neoliberal. Se, no início, os mais acometidos pela COVID-19 pertenciam às classes média e alta, hoje, o perfil da pandemia brasileira é pobre, preto, vive nas periferias das grandes cidades, ou em regiões distantes dos centros mais desenvolvidos, com menor acesso aos bens e serviços, inclusive de saúde, e é formado principalmente por pessoas com poucas chances de não serem acometidas pelo vírus ou, se infectadas, têm maior risco de morrer.

Diante disso, a Atenção Básica tem uma importante função a cumprir, uma vez que sua imersão na realidade é sua condição básica da existência.

Este capítulo tem como objetivo refletir sobre os desafios da Atenção Básica (AB) no cuidado à população brasileira durante a pandemia da COVID-19, a partir de considerações sobre a determinação social do fenômeno, com ênfase nas condições de organização e operação do sistema de saúde brasileiro.

\section{ATENÇÃO BÁSICA: DA IMPORTÂNCIA À FRAGILIZAÇÃO}

O termo "Atenção Básica" foi adotado pelo movimento da reforma sanitária brasileira para representar o primeiro nível do sistema de atenção à saúde, também conhecido como Atenção Primária à Saúde (APS), bem como para organizar e operar a porta de entrada desse sistema. A APS integra a rede assistencial de cuidados, com enfoque na comunidade e no território, revelando-se fundamental para o enfrentamento de epidemias, como no caso da COVID-19, pois envolve o conhecimento da população e suas vulnerabilidades, favorecendo as ações de promoção, prevenção e cuidado individual e comunitário(3).

O conceito pós-moderno da APS foi mundialmente veiculado em 1978, durante a Conferência Internacional sobre Cuidados Primários de Saúde, sediada em Alma-Ata, na Rússia. Naquele cenário, a APS foi definida como "cuidados essenciais, baseados em método de trabalho e tecnologias de natureza prática, cientificamente críveis e socialmente aceitáveis, universalmente acessíveis na comunidade aos indivíduos e às famílias, com a sua total participação e a um custo suportável para as comunidades e para os países, à medida que se desenvolvem num espírito de autonomia e autodeterminação (...). É parte integrante tanto do sistema de saúde do país, do qual constituem a função central e o foco principal, quanto do desenvolvimento social e econômico global da comunidade. Representam o primeiro nível de contato dos indivíduos, da família e da comunidade com o sistema nacional de saúde, pelo qual os cuidados de saúde são levados o mais proximamente possível aos lugares onde pessoas vivem e trabalham, e constituem o primeiro elemento de um continuado processo de assistência à saúde"(4:15).

Dessa definição emergiram os elementos fundamentais da APS: a educação em saúde, o saneamento básico, o programa materno-infantil (incluindo a imunização e o planejamento familiar), a prevenção de endemias, o tratamento apropriado às doenças prevalentes, o fornecimento de medicamentos essenciais, entre outros. Esses elementos apontam para uma importante fundamentação, que antecede e norteia o SUS, isto é: o entendimento da saúde como expressão de um direito humano fundamental ${ }^{(5)}$.

Na direção do recomendado em Alma Ata, no Brasil, desde 1994 e vigente até o momento, foi institucionalizado o Programa, hoje Estratégia Saúde da Família (ESF), que inaugurou novas formas de fazer saúde, contribuiu para a ampliação do acesso e a descentralização das ações e provocou mudanças das práticas profissionais e institucionais. Assim, mostrou-se fundamental para a efetivação da $A B$, priorizando a articulação de ações de educação em saúde, vigilância epidemiológica e sanitária, assistência a grupos populacionais prioritários e reorganização da atenção à demanda espontânea. 
Contudo, ainda que, em determinados períodos históricos, tenham se registrado incentivos à ESF e o crescimento do número de equipes, da cobertura populacional, da criação dos mecanismos de apoio para a formação de profissionais e prestação de cuidado multiprofissional e interdisciplinar, a situação da saúde no Brasil tem piorado muito nos últimos anos, em especial, a partir de 2016, com a mudança radical da política econômica. Exemplo disso foi a aprovação da Emenda Constitucional (EC-95), que instituiu um novo regime fiscal que vigorará até 2036 no Brasil contendo os gastos públicos. Tal política tem sido alvo de importantes protestos por parte da sociedade civil, foi motivado pela ausência de debate com o setor público, mas, sobretudo, pela oposição e resistência a um discurso oficial que apresenta a necessidade, mentirosa, de um novo regime capaz de retomar o crescimento econômico por meio da limitação de gastos e investimentos públicos, principalmente de ordem social( ${ }^{(6)}$.

Outra prova contundente de perda da noção de direito à saúde foi a nova Política Nacional da Atenção Básica, aprovada em 2017. Somada à referida PEC-95, representa um grande retrocesso na atenção à saúde da população. A despeito também de inúmeras críticas da comunidade científica e dos órgãos de controle social, foi aprovada e encontra-se em vigor, com sérias deficiências, como a não obrigatoriedade de cobertura de $100 \%$ da população, a mudança do número de Agentes Comunitários por equipe, a redução do número de equipes e a mudança gradual do modelo assistencial, desprivilegiando o monitoramento das condições de vida e saúde da população do território para incrementar cada vez mais a assistência individual, focada em agravos ${ }^{(7)}$.

O golpe mais recente, ocorrido no final de 2019, foi a aprovação da nova forma de financiamento da APS, que deixa de levar em consideração as demandas dos grupos populacionais, passa a ser restrito às pessoas cadastradas em serviços de APS e depende de resultados alcançados com base em indicadores pré-definidos, ou seja, o financiamento deixa de ser universal, contrariando de maneira inequívoca o princípio da Universalidade do SUS. Dados apresentados pelo Conselho Nacional de Saúde, revelaram que com a Emenda Constitucional (EC) número 95/2016, o financiamento do SUS teve uma redução de $R \$ 22,5$ bilhões e mais $R \$$ 20 bilhões com Restos a Pagar, ou seja, dinheiro empenhado e não aplicado de anos anteriores. A redução do financiamento do SUS não interfere somente na garantia de saúde aos cidadão brasileiros, mas também fragiliza a estrutura que mantém em funcionamento os serviços de atendimento ${ }^{(8)}$.

\section{DO BIOLÓGICO AO SOCIAL NA DETERMINAÇÃO DA PANDEMIA}

Para compreender a pandemia da COVID-19 e as diferentes crises, sanitária, política, econômica que repercutem cruelmente no agravamento da qualidade de vida e saúde da população, é pertinente e necessário refletir acerca da determinação social da saúde, objetivando superar as análises restritas ao viés biológico da doença.

Na visão da epidemiologia crítica, que se baseia na teoria da determinação social da saúde, existe uma estreita relação entre o social e o biológico na pandemia da COVID-19. Embora o vírus SARS-CoV-2 seja o elemento biológico específico da pandemia, a responsabilidade pelo processo de transformação genômica do vírus, sua transmissão entre humanos, a capacidade infecciosa e a deterioração do sistema imune de cada indivíduo são determinados socialmente. Desta maneira, ao invés da COVID-19 ser simplesmente uma doença pandêmica, trata-se de um fenômeno complexo e multidimensional, determinado histórica e socialmente, com raízes nas três dimensões da sociedade (geral, particular e individual). Na dimensão geral, destaca-se a expansão desenfreada de territórios e ecossistemas não saudáveis e baseados no extrativismo extremamente espoliador ao meio ambiente; na dimensão particular, salienta-se o acometimento maior da doença nas classes subordinadas a modos de vida de exposição e vulnerabilidade; na dimensão individual, evidenciam-se os estilos de vida individuais, propensos à exposição e ao contato, a vulnerabilidade pessoal e os estressores, bem como a contaminação com alta carga viral, a existência de comorbidades, desnutrição e a conversão de processo protetores fisiológicos em patológicos ${ }^{(9)}$. 
A articulação entre o biológico e o social é responsável por produzir as inúmeras repercussões da pandemia. Como expressado anteriormente, a agenda neoliberal governamental tem efetivado medidas que têm provocado a ampliação e o agravamento da COVID-19: a prioridade dada à esfera econômica, a fragilização dos sistemas públicos de saúde, de assistência social e previdência, a relativização da gravidade da pandemia e a não adesão às medidas de prevenção, a disseminação de informações falsas na mídia, a presença de comunidades pobres, com reduzido acesso à água tratada, saneamento e estrutura e renda, que além de agravar a pandemia por facilitar a transmissão do vírus, ainda inviabilizam ou dificultam as medidas de prevenção e tratamento ${ }^{(10)}$.

Ainda com referência à determinação social da pandemia, é importante frisar que longe de ser um evento democrático como veiculado no início, há uma inegável desigualdade em termos de condições que favorecem a contaminação e o desenvolvimento da doença nos diferentes grupos populacionais. Estudos recentes demonstram que as chances de contaminação e o risco de morrer de COVID 19 são maiores entre pobres, pardos ou pretos, menos escolarizados, idosos e homens ${ }^{(10-11)}$

\section{POTENCIALIDADES E DESAFIOS DA ATENÇÃO BÁSICA EM TEMPO DE PANDEMIA}

No contexto do SUS, a AB representa o ponto de atenção que permite o maior contato com a comunidade, por meio do reconhecimento do território. Seus atributos essenciais como, acesso de primeiro contato, integralidade do cuidado, longitudinalidade e coordenação permitem que sejam enfrentadas fragilidades sociais evidenciadas na pandemia. Dessa forma, por sua capilaridade, a AB se constitui como um serviço potente para o combate a pandemia da COVID-19, justamente por proporcionar que o social e o biológico se encontrem como totalidades partes da mesma totalidade, e não como opostos ${ }^{(3)}$.

No entanto, desde o início da pandemia, a $A B$ tem sido relegada a segundo plano, com visível privilegiamento dos serviços de alta complexidade, ambulatoriais e hospitalares, incluindo investimentos financeiros tanto públicos como privados neste setor. Isso ocorreu em detrimento dos serviços de $A B$ que, em muitos locais, diminuíram os atendimentos, suspenderam as atividades extramuros no território e deixaram à própria sorte a população desassistida. Pode-se mesmo ousar dizer que a orientação para que as pessoas sintomáticas sem gravidade permanecessem em casa contribuiu para piorar situações que poderiam ter sido lidadas precocemente, com sucesso.

Somente o desenrolar da crise com o agravamento da situação e a comprovação de que a testagem, o monitoramento e controle de comunicantes podem ser efetivos para a diminuição da pandemia têm feito com que alguns municípios e estados adotem medidas de vigilância epidemiológica há muito tempo conhecidas e implementadas em inúmeras situações epidêmicas anteriores. Há muito está comprovado que a ESF pode desempenhar uma importante função na rede assistencial no enfrentamento de qualquer epidemia, como já registrado em outros momentos da história brasileira, mesmo que em dimensões e complexidades menores que a COVID-19, como zika, chikungunya, dengue, entre outras. Essa potencialidade está assentada, sobretudo, no conhecimento que as equipes de ESF possuem do território e das vulnerabilidades da população, e na incrível capacidade de transformar processos de trabalho de forma a compatibilizar o atendimento à realidade. Essa, aliás, historicamente tem sido uma grande potencialidade das equipes na APS, dado que na maior parte das vezes não dispõem de recursos humanos e materiais necessários para o atendimento adequado. A riqueza do patrimônio humano da Atenção à Saúde e nela, da APS, é digna de nota e nessa pandemia felizmente tem sido muito ressaltada e com uma visibilidade sem igual. Mesmo menos visíveis que os serviços de grande complexidade, tem sido fundamental sua ação junto às coletividades. Que o digam as populações socioeconomicamente mais carentes!

O que tem feito muita falta é uma coordenação central - no nível do Ministério da Saúde - das equipes da $A B$ espalhadas por todo território brasileiro, em articulação com os demais serviços especializados e complementares ligados à Rede de Atenção à Saúde. Também se faz necessário ampliar o fortalecimento 
e a estruturação das redes de apoio sociais formais e informais, capazes de auxiliar a enfrentar diferentes questões e situações deletérias advindas do isolamento social e que envolvem, sobretudo, idosos, pessoas acamadas, portadores de algum tipo de deficiência, adolescentes, homens e mulheres em vulnerabilidade social de comunidades urbanas e rurais ${ }^{(12)}$.

Segundo a Associação Brasileira de Pós-graduação em Saúde Coletiva, a complexidade de ações para o enfrentamento da COVID-19 que podem ser sustentadas pela atuação da AB demanda que sejam priorizados três eixos de intervenção: o primeiro deles é fomentar ações de prevenção primária e secundária de vigilância em saúde com vistas a bloquear ou minimizar o aumento do número de casos no território; o segundo eixo consiste em oferecer suporte aos grupos com vulnerabilidades de saúde ou sociais que, sem dúvida, requererão algum tipo de apoio no transcorrer da epidemia; o terceiro eixo trata de garantir a continuidade das ações que eram desenvolvidas no contexto de promoção da saúde e prevenção de agravos no período anterior à pandemia da COVID-19. Todavia, deve-se ter em mente que é preciso priorizar a continuidade do isolamento e do distanciamento social, quando possível. Por isso, para reduzir índices de aglomeração e contatos presenciais desnecessários, abre-se a possibilidade de investir em novas ferramentas e estratégias do cuidado, como a promovida pelo contato telefônico de monitoramento no cenário da $A B^{(3)}$.

Reforçando ou agregando ao foi exposto, podem ser enumerados como desafios da AB:

1. Dar ênfase à vigilância epidemiológica no território para detecção precoce dos casos de COVID-19 e efetuar todas as intervenções subsequentes visando ao controle e monitoramento do agravo em termos de educação para a saúde, isolamento de comunicantes, e as demais ações preconizadas em caso de epidemias.

2. Implementar a atenção integral à saúde, garantindo o acesso universal e equânime aos serviços públicos.

3. Estabelecer e fortalecer as redes de cuidado à população, estabelecendo parcerias com grupos organizados da coletividade, organizações sociais existentes no território e outros.

4. Reorganizar o processo de trabalho, fornecendo materiais e equipamentos suficientes para garantir a atenção à saúde da população com efetiva proteção dos profissionais e suas famílias e contatos.

5. Criar e implementar plataformas de monitoramento coletivo das condições de vida e saúde da população do território.

6. Organizar teleconsultas e teleapoio, formar grupos de usuários em aplicativos para smartphone, com acompanhamento de grupos à distância, visando reduzir o atendimento presencial, sem perder contato com a população.

7. Formar, capacitar e qualificar adequadamente todos os profissionais envolvidos no atendimento dos usuários, tentando superar as limitações do ensino não presencial e o uso de plataformas digitais.

8. Estabelecer parcerias com outras instâncias e setores governamentais para estabelecer programas de suporte social às populações dos territórios visando minimizar os impactos econômico-financeiros sobre as populações mais vulneráveis.

\section{CONSIDERAÇÕES FINAIS}

De certo modo, a pandemia da COVID-19 propiciou que o mundo olhasse com mais cautela e atenção para o cuidado à saúde, não exclusivamente enquanto embate contra um agente biológico específico, mas também com reconhecimento dos impactos provocados pelos sistemas econômicos, políticos e sanitários, na própria determinação da pandemia. Dialeticamente, esse fenômeno tem agravado cada vez mais as crises desses mesmos sistemas. De outra parte, o enfrentamento da pandemia revelou potencialidades e limites dos níveis de atenção à saúde, com vistas à superação rápida e efetiva do problema emergente.

O capítulo ressaltou que decisões políticas e econômicas assumidas no passado, mesmo que recente, influenciaram as condições de saúde presentes e irão interferir também nas medidas futuras. Acredita-se que 
o enfrentamento da COVID-19 provocará transformações pós-pandemia em toda a sociedade, incluindo-se aí a maneira de conceber e fazer saúde nos seus diversos níveis, com destaque para a Atenção Básica.

O enfrentamento da COVID-19 tem revelado uma situação complexa que certamente envolve a reflexão sobre a estruturação e o funcionamento dos serviços que constituem a rede de atenção à saúde. Evidenciou ainda mais o importante papel que ocupa na coordenação e monitoramento do cuidado com base nos princípios do Sistema Único de Saúde concretizados a partir da situação epidemiológica da população dos territórios, marcados por heterogeneidades acentuadas pela alquimização das categorias sociais de gênero, geração, classe social e raça-etnia.

Em síntese, em termos de Atenção Básica, no panorama atual de enfrentamento da pandemia, o grande e primaz desafio que se coloca é possibilitar o cumprimento das suas ações, no mesmo nível em que o fazem os serviços de maior complexidade, com a mesma visibilidade, com o mesmo quantum de investimentos em recursos humanos, materiais, insumos e tecnologias, de forma que possam ser reconhecidas e desenvolvidas suas potencialidades. Se no campo do tratamento da COVID-19 ainda há muito a descobrir, no âmbito da $A B$, além da vacinação específica ainda não conseguida, a implementação de medidas já largamente conhecidas pode contribuir enormemente para o enfrentamento da pandemia. Por que isso não é feito?

São muitas as possíveis respostas, mas parafraseando Ignácio de Loyola Brandão ${ }^{(13)}$, tendem a ser "propositalmente desestruturadas, algo caótico, porque retrata tempos que vivemos, não sabemos onde ir, o que fazer, pensar, para onde ir, de quem esperar. O que fazer muitos sabem e têm nas mãos os poderes. Mas não fazem. Não querem. O que aconteceu, gente?"

\section{REFERÊNCIAS}

1. Pondé LF. Até onde vai nossa autonomia quando agimos em nossa vida? Folha de S. Paulo [Internet]. 2020 jul. 19 [citado 2020 jul. 22]. Disponível em: https://www1.folha.uol.com.br/colunas/luizfelipeponde/2020/07/ate-onde-vai-nossa-autonomiaquando-agimos-em-nossa-vida.shtml?utm_source=newsletter\&utm_medium=email\&utm_campaign=newscolunista

2. Brasil. Coronavírus (COVID-19). Estatísticas no Brasil e no Mundo [Internet]. Brasília; 2020. [citado 2020 Jul 22]. Disponível em: https://www.coronavirus.com.br/

3. Associação Brasileira de Saúde Coletiva (ABRASCO). Desafios da APS no SUS no enfrentamento da Covid-19. Seminário Virtual Rede APS Abrasco [Internet]. Rio de Janeiro; 2020. [citado 2020 Jul 22]. Disponível em: http://www.abeno.org.br/ arquivos/downloads/ABRASCO.pdf

4. Organização Mundial da Saúde. Conferência Internacional sobre Cuidados Primários de Saúde. Alma-Ata [Internet]. URSS; 1978. [citado 2020 Jul 18]. Disponível em: http://bvsms.saude.gov.br/bvs/publicacoes/declaracao_alma_ata.pdf

5. Mendes EV. A construção social da Atenção Primária à Saúde. Brasília: Conselho Nacional de Secretários de Saúde CONASS. [Internet] 2015. [citado 2020 Jul 20]. Disponível em: https://www.conass.org.br/biblioteca/pdf/A-CONSTR-SOCATEN-PRIM-SAUDE.pdf.

6. Mariano CM. Emenda constitucional 95/2016 e o teto dos gastos públicos: Brasil de volta ao estado de exceção econômico e ao capitalismo do desastre. Rev. Investig. Const. [Internet]. 2017 [citado 2020 Jul 22];4(1). Disponível em: http://www. scielo.br/scielo.php?script=sci_arttext\&pid=S2359-56392017000100259\&lng=en\&nrm=iso

7. Brasil. Ministério da Saúde. Portaria n. 2.436, de 21 de setembro de 2017. Aprova a Política Nacional de Atenção Básica, estabelecendo a revisão de diretrizes para a organização da Atenção Básica, no âmbito do Sistema Único de Saúde (SUS). In: Ministério da Saúde. Brasília; 2017. Disponível em: https://bvsms.saude.gov.br/bvs/saudelegis/gm/2017/prt2436_22_09_2017.html

8. Conselho Nacional de Saúde. Recomendação n. 020, de 07 de abril de 2020. Recomenda a observância do Parecer Técnico n. 128/2020, que dispõe sobre as orientações ao trabalho/atuação dos trabalhadores e trabalhadoras, no âmbito dos serviços de saúde, durante a emergência em Saúde Pública de importância nacional em decorrência da doença por Coronavírus. In: Conselho Nacional de Saúde. Brasília; 2020. Disponível em: http://conselho.saude.gov.br/images/ Recomendacoes/2020/Reco020.pdf

9. Breilh J. SARS-CoV2: rompiendo el cerco de la ciencia del poder. In: Posnormales: pensamiento contemporáneo en tiempos de pandemias [Internet]. Buenos Aires: ASPO, 2020. 388p. [citado 2020 Jul 16]. Disponível em: https://drive.google.com/ file/d/1COvZyVpJFVNEs0zRm_kMhaMtx3j_aJn5/view 
10. Souza DO. The COVID-19 pandemic beyond Health Sciences: reflections on its social determination. Ciênc. saúde coletiva [Internet]. 2020 [citado 2020 Jul 16]; 25 (1): 2469-2477. Disponível em: https://doi. org/10.1590/1413-81232020256.1.11532020

11. Baqui P, Marra V, Ercole A, Van der Chaar M. Ethnic and regional variations in hospital mortality from COVID-19 in Brazil: a cross-sectional observational study. Lancet Global Health [Internet]. 2020 [citado 2020 Jul 23];8:e1018-26. Disponível em: https://doi.org/10.1016/S2214-109X(20)30285-0.

12. Rede de Pesquisa em APS. Fortalecer a Estratégia Saúde da Família no enfrentamento da COVID-19: posição da Rede APS da Abrasco. [Internet] Boletim da Rede APS maio de 2020 [citado 2020 Jul 20]. Disponível em: https://www.abrasco.org.br/ site/noticias/especial-coronavirus/fortalecer-a-estrategia-saude-da-familia-no-enfrentamento-da-covid-19/47785/

13. Brandão IL. Se eu morrer, saibam quem me matou. O Estado de São Paulo [Internet]. 2020 mai. 22 [citado 2020 Jul 22]. Disponível em: https://cultura.estadao.com.br/noticias/geral,se-eu-morrer-saibam-quem-me-matou,70003310425 